Further Section

Confin neurol 1974;36:373

\title{
Author Index Vol. 36, 1974
}

Afshar, F. 341 Aizerman, M. A. 356 Andreeva, E. A. 356 Andy, O. J. 106

AtMnson, R. 101

Bates,J. 310 Becker.D. P. 101 Bergonzi, P. 5 Bertrand, G. 312 Birg, W. 326, 334

Blank, A. 1 Blumer, D. P. 125 Bomstein, B. 69 Brown, J. W. 33 Burg, D. 347

Chaco, J. 1,182 Chang, A. E. 61 Chapanis, N. 113 Chiurulla, C. 5 Cianchetti, C. 5

Dinakar, I. 362 Driollet, R. 355

Eytan,S. 69

Fox, J. L. 97

Gega,A. 363 Gillingham, J. 362 Giurintano, L. P. 106 Grofova, I. 256 Gucer, G. 113 Gybels,J. 302 
Hassler, R. 237 Hayashi, K. 363 Hoefer, T. 334 Hori, Y. 363

Jurko.M. F. 106

Kanazawa, I. 273 Kanazawa, K. 363 Kandel.E. I. 356 Kempen, D. 302 Koeze, T. H. 341 Konigsmark, B. 88,113

Laponogov, O. A. 371 Lücking, C. H. 347

Mark, V.H. 125 Martinez, J. 101 Mason, T. H. 79 Matz, Sh. 69 Mehler, W. R. 205 Mundel, G. 23 Mundinger, F. 326, 334

Nadvornflc,P. 177 Narabayashi, H. 292 Nauta, W. J. H. 205 Nittner, K. 360

Ohye, C. 314 Olivier.A. 312 Orlando, J. 355

Peluso, F. 302 Peter, A. 186 Poirier,L. J. 223 
Reif-Kohn, R. 23 Reinke, M. 334 Rinvik,E. 256 . Romodanov, A. P. 371

Saito.Y. 314 Sakalas, R. 101 Schvarcz, J. R. 355 Shafranova, E. I. $356^{1}$ • Sramka, M. 177 Struppler, A. 347

Tempesta, E. 5 Tenenbaum, L. A. 356 Thompson, C. J. 312 Toyokura, Y. 273

Uematsu, S. 88,113 Utsumi, S. 363

Vanbael,M. 302 Velho, F. 347 Vines, F. S. 101 Vries, J. K. 101

Walker, A. E. 88, 113 Walsh, E. G. 362 Watkins,E. S. 341 Williams, H. W. 125 Wilson, D. H. 61 Wright, G. 362

Yamaga, K. 363 Young, H. F. 101 Ypshida, M. 282 